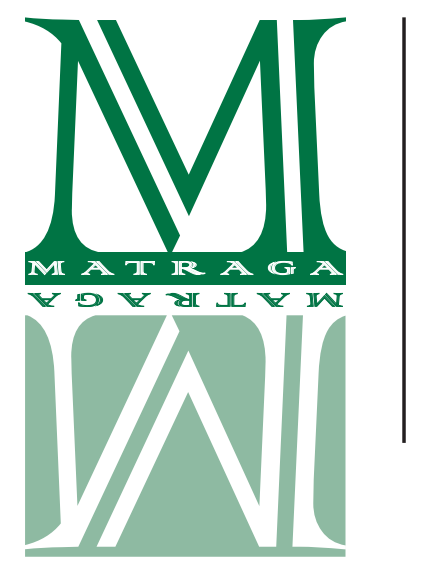

\title{
Poesia e racismo em tempos de COVID-19
}

\author{
Júlia Fernandes Caixeta \\ Universidade Federal do Rio de Janeiro (UFRJ)
}

https://orcid.org/0000-0003-2267-8974

\section{RESUMO}

Este artigo pretende falar de poesia em tempos de incerteza: pandemia, preconceito e política, e, busca verificar como o testemunho do racismo, da necropolítica e do biopoder, em tempo de COVID-19, tem afetado à população negra ao debruçar-se sobre a seguinte questão: por que ainda é necessário dizer que as vidas negras importam? Com o intuito de estabelecer um diálogo no campo teórico, o estudo traz à luz da reflexão conceito relacionado ao biopoder, na acepção de Michel Foucault e o conceito de necropolítica veiculado por Achille Mbembe, além de outras críticas, aportes teóricos e estudos pertencentes aos campos da teoria literária e dos estudos culturais.

PALAVRAS-CHAVE: Racismo de Estado; Pandemia; Poesia

\section{Poetry and Racism in Times of COVID-19}

\section{ABSTRACT}

This article intends to discuss poetry in times of uncertainty: pandemic, prejudice and politics, and seeks to verify how the testimony of racism, necropolitics and biopower, in the time of COVID-19, has affected the black population when looking at the following question: why is it still necessary to say that black lives matter? In order to establish a dialogue in the theoretical field, the study brings to light the concept related to biopower, in the sense of Michel Foucault and the concept of necropolitics conveyed by Achille Mbembe, in addition to other criticisms, theoretical contributions and studies belonging to the fields of literary theory and cultural studies.

KEYWORDS: State racism; Pandemic; Poetry 


\section{Tempos de incertezas: a COVID-19, a necropolítica e o biopoder}

A COVID-19 traz à cena um tempo de incertezas no Brasil: contágios, falta de estrutura no sistema de saúde, colapso no setor econômico, fome, miséria, escassez, morte. Mas traz também, "solidão e individualidade e a dualidade do nosso tempo em que o outro se tornou praticamente o inimigo." (SENNETT, 2014, capa). A citação de Richard Sennett caracteriza o Declínio do Homem Público, e, ao entretecê-lo à pandemia, percebe-se um paralelismo ao referir-se ao Estado Federativo e à criminalidade preconceituosa concomitantemente. Conduzindo "o homem à reflexão sobre sua relação de responsabilidade com o outro e com o ambiente, sendo que decide quais enunciados escutar ou refutar" (BERTOLI; BISSACO, 2018). Ao trazer a criminalidade como objeto faz-se alusão aos negros, aos pobres e aos jovens. Em um cenário de "quase guerra", o Estado decide direta ou indiretamente, quem tem o direito de continuar vivo seja à maneira que enfrenta a pandemia, seja à maneira que administra a criminalidade. Então, é necessário, trazer à luz o conceito de necropolítica, a fim de compreender a relação de mortes aos periféricos: os negros, os pobres e os jovens e atrelar a esse conceito o racismo de Estado, pois, esse conceito tem sido utilizado para compreender a relação entre o Estado e um padrão de genocídio de povos negros e pobres. A poesia "Corpo Levado" de Bia Ferreira ${ }^{1}$ ilustra esse conceito:

\footnotetext{
Correria [...] / Bobeou eles atira / Eles nem são bons de mira / Mas a ordem é matar / "Se não é alvo, aniquila / Porque o alvo é a melanina / Pode estar com a família, / Menino ou menina” / E na favela é mais uma chacina / Necropolítica / No hospital /

Não tem respirador e maca / Tá faltando luva e máscara / Quando que isso vai melhorar? / Indígenas exterminados / O garimpo liberado / Na terra que seus antepassados começaram a plantar. / Lamas varrendo cidades / Aviso prévio da morte / Agora pensa se VALE / Calcular e deixar a sorte / [...]/ Toda essa bomba relógio / Isso é Necropolitica

Mbembe me ensinou / E eu tô repassando agora! / Cheguei falando alto, agora tô fazendo alarde/ Espero que entenda e comece a sua parte! / Por quê Não vai chorar sua mãe / Nem vai chorar a minha / Povo preto se armando / Com a palavra e a escrita / Não vai chorar sua mãe / [...] / Povo preto se armando / Conhecimento é a saída." (NECROPOLÍTICA - Bia Ferreira - cantora)
}

Neste poema, a artista Bia Ferreira aborda o contexto do combate armado, descrevendo o funcionamento de guerra pelo Estado. Observa-se que o fazer político, reconhecido por vezes, como ato democrático, é denunciado pela autora como aquele que detém o direito de matar: "Mas a ordem é matar", "águas e comidas toxicas, querem te intoxicar".

O Estado, ao reconhecer o seu inimigo, declara guerra como um pressuposto para validar uma ação política. Dentro dessa configuração, entende-se o que a poeta quer dizer com "Necro-

\footnotetext{
1 Cantora, brasileira, Carangola, Mineira, compositora, multi-instrumentista, ativista, Bia Ferreira prefere mesmo se definir como "artivista". "Gosto de usar várias ferramentas. Minha pretensão de vida é conseguir viver, até o fim, de arte, independente de ser cantando, compondo, produzindo, arranjando ou sendo musicista. 0 poema foi transcrito pela autora do artigo da página do facebook - Disponível em: <https://www.facebook.com/watch/?v=265634761483542>. Acesso em: 25 nov. 2020 e da Rede Brasil Atual - Disponível em: <https://www.redebrasilatual.com.br/ cultura/2019/12/bia-ferreira-poe-sua-arte-a-servico-da-luta-contra-0-sistema-opressor/>. Acesso em: 25 nov. 2020.
} 
política é isso", o Estado possui o poder de definir a morte dos indivíduos com base na separação, vigilância, controle dos corpos e territórios.

"Populações inteiras são alvo do soberano. As vilas e cidades sitiadas são cercadas e isoladas do mundo.

A vida cotidiana é militarizada. É outorgada liberdade aos comandantes militares locais para usar seus próprios critérios sobre quando e em quem atirar." (MBEMBE, 2019, p.48)

Para Mbembe o genocídio da população negra evidencia a existência de uma máquina responsável por definir aqueles que devem estar mais expostos à exclusão das estruturas sociais e políticas. O ensaio Necropolítica: biopoder, soberania, estado de exceção, política da morte, de Achille Mbembe, apresenta uma reflexão sobre a "expressão máxima de soberania, concebida como o poder e a capacidade de ditar quem pode viver e quem deve morrer" (MBEMBE 2018: 5). É uma obra que dialoga com Frantz Fannon e Michel Foucault por referir-se à Ciência Política, à Filosofia e à Antropologia, pois analisa fatos sociais que envolvem situações de guerras e violências. Mbembe é Professor de História e Ciência Política nas Universidades de Witwatersrand em Johanesburgo e Duke University nos Estados Unidos. Também ocupa o cargo de diretor de Pesquisa Social e Econômica no Instituto Witwatersrand, em Joanesburgo - África do Sul. O ensaio traz reflexões sobre uma nova forma de exercício do poder que o autor denomina de necropolítica, cuja configuração singular estaria imbricada ao processo do 'dever do sujeito' nas sociedades atuais marcadas pelo fortalecimento do neoliberalismo. Mbembe em consonância com o pensamento do filósofo Michel Foucault (2006), afirma que em "certa medida ser soberano é exercer controle sobre a mortalidade e definir a vida como a implantação e manifestação do poder" (MBEMBE 2018:5).

O que é biopoder? "Direito de morte e poder sobre a vida" afirmou (Foucault, 1978, p. 137). Percebe-se que o conceito de biopoder se funde ao de necropolítica e para Mbembe o racismo de Estado é em si "o motor do princípio necropolítica” (MBEMBE, 2017, p.65), é o motor desta guerra que expressa o modus operandi do Estado brasileiro que é pragmático quando se confronta com corpos negros. Essa perspectiva discute com o conceito foucaultiano de biopoder, ressaltando o racismo como elemento central do exercício do poder estatal, legitimando o direito de deixar morrer e/ou de matar, em nome da sustentação de determinados modos de reprodução de outras vidas mais legítimas. Para Achille Mbembe "a característica mais original dessa formação de terror é a concatenação entre biopoder, o estado de exceção e o estado de sítio. A raça é, mais uma vez, crucial para este encadeamento" (MBEMBE, 2018, p. 31). Em outras palavras, trata-se de outras configurações de existência social em que as populações apresentem condições de vida que as conferem estatuto de "mortos-vivos", (MBEMBE, 2018, p. 71).

\subsection{0 poema de João Pedro, de Ágatha, de Kauê, de Kauan, de João Alberto}

Ao trazer esses conceitos como mote de pesquisa, trazemos recortes de casos reais que aconteceram no Brasil, que elucidam que o Estado tem delegado a uns o direito de viver e a outros não. Falaremos de poesia para expressar, em palavras, o estado de guerra. No dia dezenove de 
maio de 2020 foi encontrado o corpo de João Pedro, adolescente de 14 anos, assassinado em decorrência de uma intervenção policial, no Complexo do Salgueiro, em São Gonçalo, no Rio de Janeiro (BARBON, 2020). Após ser atingido, o corpo do jovem, foi levado no helicóptero da polícia, sem o consentimento dos familiares, onde só tiveram a notícia da morte na manhã do dia seguinte (BARBON, 2020). Nesse mesmo dia, no Brasil, confirmavam-se a morte de 16.000 mil pessoas por COVID-19, das quais $54,8 \%$ dos mortos eram pessoas negras (Brasil, 2017). Em tempo, "Ágatha Félix - de 8 anos; Kauê Ribeiro dos Santos - de 12 anos; Kauan Rosário - de 11 anos, segundo levantamento da ONG: Rio de Paz" (AUN, 2019, acessado em: 21/11/2020) também morreram vítimas de balas perdidas no mesmo período no Rio de Janeiro.

A situação repercutiu e revoltou muitas pessoas, acerca da ação policial indiscriminada, sobre a população negra do país. Tal situação denuncia que a política de segurança pública está intimamente ligada à política da morte adaptada pelo Estado. A identificação do inimigo se dá com base em elementos que compõem o tecido social, chamada por Mbembe (2018) de política da raça, estes avaliados pelo olhar disciplinador entrecruzam e estabelecem modos de reconhecimento e/ou exclusão da humanidade na vida dos indivíduos. O corpo do jovem carioca, que ao ser assassinado, teve o seu "corpo levado" pelo Estado.

O "corpo levado" também se constitui como um corpo subversivo, que rompe com a cadeia de enquadramento proposta e representa o símbolo de perigo ao poder hegemônico. Estando aí, o então inimigo do Estado.

Poema de João

"João era jovem como nós. / João tinha os olhos despertos,/ os ouvidos bem abertos,/ as mãos estendidas para a frente,/ a cabeça projectada para amanhã, /a boca a gritar "não" eternamente.../ João era jovem como nós/ e era sangue e suor das multidões,/ e se confundia com Moçambique,/ e era uma águia que nascera para voar,/ e odiava as jaulas e os homens que as fizeram,/ e porque João era jovem e ardente como nós,/ ah, por isso tudo, perdemos João./ Perdemos João,/ por isso gritamos noite e dia por João,/ por João que nos roubaram./ [...] /Mas que importa?/ Que importa? /Julgam que o roubaram,/ mas João está conosco,/ esta nos outros que virão,/ está nos que já estão vindo,/ Porque João não é só,/ João é multidão, /João é sangue e suor de multidões, /E João, sendo João, /tambem é Joaquim, José, Abdula ... /E quem poderá levar José, Joaquim Abdula?/ Quem?/ Quem poderá levar-nos todos e fechar-nos todos numa jaula?/ Ah, roubaram-nos João, /mas João somos nós todos,/ por isso João não nos abandonou.../ E João não “era”, “ẹ” e "será",/ porque João somos nós,/ nós somos multidão, /e multidão,/_ quem pode levar multidão e fechá-la numa jaula? (SOUSA, 2001, p. 116).

A poesia é o veículo escolhido para narrar as vidas. Narramos nossas vidas com a vida dos outros, pois não há poesia sem multidões. Ao criar uma poesia registramos e expressamos a "demanda revolucionária, a implementação da liberdade", de uma vontade de existir (LORDE, 2019 , p.48). Sobre essa vontade de existir, trazemos à luz, o que ocorreu no dia 20 de novembro de 2020, Dia da Consciência Negra, “[...] a Vila do IAPI, no bairro Passo d’Areia, em Porto Alegre, também, será sempre lembrada como o lugar onde morava João Alberto Silveira Freitas, 40 anos, o João Beto. Vimos o assassinato ocorrido em uma conhecida cadeia de supermercados". 
(CAMPOS, 2020. Acessado em: 22/11/2020). Ainda não se sabem os motivos que levaram o "Beto" a ter a sua vida ceifada, no entanto, mais um negro morre sem direito à defesa:

\begin{abstract}
"A funcionária abordada por João Alberto Silveira Freitas prestou depoimento como testemunha no inquérito que apura a morte do cidadão negro, espancado por dois seguranças brancos na quinta-feira (19), no estacionamento de uma unidade do Carrefour, em Porto Alegre". [...] "A mulher da vítima aparece 30 segundos depois e tenta socorrer o marido, mas é impedida pelos seguranças. Em depoimento, ela contou que Beto dizia "Milena, me ajuda", e que quando ela tentou socorrê-lo, foi empurrada por um dos rapazes".

Depois disso, apesar dos apelos da mulher, Giovane, Magno e um funcionário de branco continuam em cima do homem. Segundo a polícia, os seguranças ficaram sobre Beto por cerca de 5 minutos. O laudo preliminar da necropsia constatou que as lesões no corpo da vítima eram superficiais, e a causa mortis provavelmente é asfixia”. (CAMPOS, 2020, acessado em: 22/11/2020).
\end{abstract}

Mediante ao exposto acima, relembramos a morte brutal que gerou comoção e protestos em vários países, de outro negro: George Floyd, morto brutalmente asfixiado nos Estados Unidos, em junho de 2020: “' [...] Eu não consigo respirar'. Floyd, um cidadão negro de 46 anos, morreu depois de ter sido imobilizado por um policial branco que pressionou o seu pescoço por mais de nove minutos, mesmo quando não respondia mais". (INTERNACIONAL, 2020, Acessado em: 23/11/2020).

Além do grande número de mortes, a presença dessa população se encontra em maioria na exposição aos trabalhos informais, nos índices de desemprego, nas situações de extrema vulnerabilidade social, que impossibilita o isolamento em tempos pandêmicos. Um dos recursos possíveis torna-se a arte do falar. Considerar a funcionalidade cotidiana da poesia, como instrumento de fala e arma, na vida das pessoas pretas, frente aos episódios de massacre (MENDONÇA, 2020), instaurados pela política genocida e o uso desta como poder bélico, torna-se um viés que enfraquece as práticas que dominam a existência e censuram os dizeres.

Ao retomar a poeta, Noémia, com sua voz tomada de força, o então conhecido "Poema de João" nos ocupa de multidões. Noémia não fala para uma pessoa. Noémia fala para um grupo, uma multidão. Noémia não fala só sua própria história, mas uma história que pode ser partilhada por tantas/os pretas/os Brasil afora. Noémia fala para /e de João Alberto, de João Pedro, de Ágatha, de Kauan, de Kauê. O que está na fala dessa poeta moçambicana é a condição de que tudo "nasce e morre naquilo que se fala", por isso, "estamos condenados a linguagem mesmo depois de perdermos o corpo" (COUTO, 2011, p. 14). Esta pode ser uma das condições que afirma o racismo como operador de morte de inúmeras vidas negras no Brasil, no curso de sua história colonial.

O existir no mundo acompanha o som de fala; fala que acompanha o sistema de ideias que anuncia ou não uma possibilidade de saída do território que vivemos, como nos diz Noémia. “O ato de falar está completamente vinculado a uma cultura e no fato de sustentar o fardo de uma civilização" (FANON, 2008, p.103). Com isso, falamos "português", por isso, colocamos em palavras de onde falamos: das periferias, das ruas, dos centros e dos subúrbios, da capital e dos interiores, da América e de África. Falamos de tantos lugares buscando a "possibilidade de existências para além das impostas pelo regime discursivo dominante" da supremacia branca (RIBEIRO, 2019, p. 89). 
Onde se fala, a dor condensada torna-se operador de vida e justiça, "quem pode levar multidão e fechá-la numa jaula?" (SOUSA, 2001, p. 120). A palavra é combustível para o corpo. A palavra é a vida. No corpo do falante a palavra é um afeto tomado em sentido, modos circular de partilha. De um a um a palavra se move. Afinal, como demonstra Kopenawa "as palavras são antigas, mas nunca vão desaparecer, porque são muito bonitas e o valor delas é muito alto" afinal, pode ser que para nós, de orientação ocidental, as palavras "segurem o céu para que ele não desça" (KOPENAWA, 2015, p. 85).

Como dito anteriormente, uma poesia se diz com as multidões, sejam eles dentro ou fora de nós. Para o mundo: destino da poesia. Uma exterioridade capaz de reivindicar a presença com a fala. Conceição Evaristo descreve esse modo usando o termo "escrevivência": experiência de cartografar a vida por entre as malhas da ficção, nesses percursos, viver é em tudo experimentar uma invenção, afinal, a "memória esquece, e por isso a necessidade da invenção". Falar é inventar a si mesmo (EVARISTO, 2017, prefácio).

$\mathrm{Na}$ medida em que se diz, em que se narra o nome de todas as pessoas mortas por COVID-19, por ações criminosas da segurança pública, por fome, por insalubridade, um sentido é produzido e dado as multidões. O luto então se estabelece partido, ora pergunta o "porquê" outrora o "quem das coisas" (ROSA, 2019, p.302). Quando perguntam o "por quê" o luto estabelece uma sincronia com a geografia. Por que ele morreu?"; "porque estava no lugar errado", se responde sobre o corpo preto assassinado. Mas qual é o então lugar do preto? Onde ele quiser. Quando se pergunta "quem?" o luto vincula-se a história. É no "quem das coisas" que o nome se propaga de ouvido para ouvido. "Morreu o filho de fulana-de- tal”, "aquela criança?", "aquela criança que brincava aqui na porta com nossos filhos". Quem morreu? Uma criança negra de 14 anos assassinada por uma ação policial.

Aí está a poesia, acionada no tempo em que a vida corre o risco de perder seu encanto, afinal, “o contrário da vida não é a morte”, mas, “o desencanto" (SIMAS \& RUFINO, 2020, p.11). A poesia é esse jeito de denunciar, uma "astúcia de batalhas e mandingas em um mundo assombrado de terror" (SIMAS \& RUFINO, 2020, p.8). A poesia é aquele meio capaz de "arvorecer com a delicadeza do jardineiro e a fortaleza de mil anos das sumaúmas da oresta, agir como folha de espinheira-santa em suas artimanhas de guerra" (SIMAS \& RUFINO, 2020, p.17). A poesia é o povo em cada som, ruído. Mecanismo de força, operador de sentido. Em tudo, a possibilidade de dizer sobre outros mundos, localizar a geografia e nomear a história.

São esses e outros modos de coletividade que a branquitude busca a destruição. Me parece que a necessidade é de deteriorar a grandeza das coletividades. A pergunta "O que quer o humano?" nos coloca na enrascada futurista em tempos de pandemia. "Não saber" é uma postura firme que se coloca frente a própria a vida, "O humano não sabe o que quer". A astúcia da questão produz interface com o íntimo de cada um de nós: "ora, mas sei o que quero" diria, bastou a pandemia chegar e logo nos asfixiar de "não saber".

A poesia é um anti-limite desse "não saber", o poeta é um armado em disputa pelo sentido da vida. A poesia é invenção da letra, do nome, do corpo. Assim como a música e seus rituais, a poesia "cria um modo pelo qual a identidade não pode ser entendida nem como essência fixa, nem como construção vaga" (GILROY, 2012, p. 209). Ela rompe os caprichos do "eu sou" e pos- 
sibilita ao corpo o estatuto do "estou", é uma "tecnologia emergente sobre o corpo", intensifica a "linguagem, gestos, significações corporais, desejos". A poesia insurge no corpo como uma identidade, ou seja, "ela existe, tem realidade, é permanentemente produzida em torno, sobre, dentro do corpo pelo funcionamento do poder que é exercido" (FOUCAULT, 2014, p.29).

Então, o genocídio, a eliminação física em escala industrial dos corpos negros que habitam vidas que não convém aos interesses do Estado é a expressão final do racismo de Estado que delimita e faz o corte entre o que deve viver e o que deve morrer em uma sociedade de normalização, onde, verdadeiramente o normal é Ser branco ou no mínimo similar.

Portanto, percebe-se que os conceitos enveredados sobre o racismo de Estado e a necropolítica, contribuem para entender de maneira a população negra tem morrido, em tempo de COVID-19 que não seja por vírus, em especial a juventude, pelo Estado com comoção social e uma devida atenção das mídias sociais.

\section{\#vidasnegrasimportam 2}

O papel do intelectual não é mais o de se posicionar "um pouco a frente e um pouco ao lado" para dizer a verdade muda de todos; é antes o de lutar contra as formas de poder ali onde ele é, ao mesmo tempo, o objeto e o instrumento disso: na ordem do "saber", da "verdade", da "consciência", do "discurso". (FOUCAULT, 2006, p. 39).

O Estado é uma máquina de guerra, que reinsere a guerra presente no corpo social nas suas dinâmicas e instituições, buscando pelo dispositivo do racismo e suas diferentes vias, eliminar, calculadamente, as vidas que ele estipula serem vidas perigosas para a saúde social que ele protege.

Neste sentido, pensar com Michel Foucault e Mbembe e os demais autores utilizados, as vias pelas quais o Estado condena à morte, algumas vidas, tendo como alicerce os conceitos de biopoder, racismo de Estado e necropolítica, permitem visualizar o modo como se dão as relações de poder entre o Estado e os indivíduos em uma sociedade de segurança, que assegura apenas alguns. Como também, permite inserir no pensamento filosófico-político, a discussão contemporânea sobre as consequências do excesso de poder do Estado sobre a vida, que em nossa realidade, subjuga à morte vidas negras. Fato que pode ser constatado no decorrer desse artigo, como também no Relatório final da $\mathrm{CPI}^{3}$ do Senado sobre o Assassinato de Jovens no Brasil que fora publicado em 2016.

\footnotetext{
2 \#vidasnegrasimportam é uma hashtag que surge devido a campanhas do Movimento Negro, como de organizações como as Nações Unidas pelo fim do genocídio da juventude/população negra no Brasil. No entanto, esta campanha é influenciada pelo movimento afro-americano Black Lives Matter nos Estados Unidos, que desde 2013, luta contra a violência policial direcionada a pessoas negras. Sobre a Campanha Vidas Negras da ONU conferir em <https://nacoesunidas.org/vidasnegras/>

${ }^{3}$ Segundo o relatório final da CPI de Assassinato de Jovens, no Brasil "os homicídios dolosos são uma triste realidade: 56.000 pessoas são assassinadas todos os anos no País, o que equivale a 29 vítimas por 100.000 habitantes, índice considerado epidêmico pela Organização das Nações Unidas (ONU). Este patamar vergonhoso e preocupante tem se mantido inalterado ao longo de três décadas, com pequenas variações. Importante salientar que a vitimização apresenta padrões particulares: $53 \%$ das vítimas são jovens; destes, $77 \%$, negros e $93 \%$ do sexo masculino. 0s homicídios dolosos são a primeira causa de morte entre os jovens. Ademais, o risco não se distribui aleatória e equitativamente por todos os segmentos sociais e raças, ao contrário, concentra-se na camada mais pobre e na população negra, reproduzindo e aprofundando as desigualdades sociais e o racismo estrutural." (RELATÓRIO CPI ASSASSINATO DE JOVENS, 2016).
} 


\section{Considerações finais}

Este artigo demarca um genocídio da população negra, conforme os índices de mortalidade que atingem níveis de países em guerra. Portanto, constata-se que o genocídio é o sonho dos poderes modernos, e pode-se dizer contemporâneos, "porque o poder se situa e exerce ao nível da vida, da espécie, da raça e dos fenômenos maciços da população" (FOUCAULT, 1988, p.149150) e o xeque-mate do racismo de Estado, o dispositivo da morte, é a aniquilação física dos indivíduos construídos como inimigos.

Os jovens negros lutam diariamente para terem expectativas de vida, pois bem sabem o que é nascer tendo perspectivas de morte, no Brasil. O racismo de Estado, que pode ser compreendido por racismo institucional, historicamente, ceifa vidas e sonhos. Mas, é necessário, tomar medidas multidimensionais - políticas públicas que visam o coletivo sem distinção de classe e cor. É preciso, desconstruir essa visão binária que sustenta as relações para que todos continuem a existir e verdadeiramente viver.

Reconhecer que o racismo é o motor das relações, e, que através do poder de fala veiculada de várias maneiras, como a poesia de Noémia por exemplo, ou a expressividade das músicas da cantora Bia, é um meio de dar voz aos menos privilegiados.

\section{REFERÊNCIAS}

AUN, Heloísa. A sociedade não está preocupada com a morte de Ágatha. 2019. Catraca Livre. Disponível em: $<$ https://catracalivre.com.br/cidadania/a-sociedade-nao-esta-preocupada-com-a-morte-de-agatha/>. Acesso em: 20 nov. 2020.

BARBON, Júlia. Laudo indica que tiro de fuzil atingiu João Pedro pelas costas. Folha UOL. Disponível em $<$ https://www1.folha.uol.com.br/cotidiano/2020/05/laudo-indica-que-tiro-de-fuzil-atingiu-joao-pedro-pelas-costas.shtml>. Acesso em: 26 nov. 2020.

BRASIL. Presidência da República. Secretaria de Governo. Índice de vulnerabilidade juvenil à violência 2017: desigualdade racial, municípios com mais de 100 mil habitantes. Secretaria de Governo da Presidência da República, Secretaria Nacional de Juventude e Fórum Brasileiro de Segurança Pública. São Paulo: Fórum Brasileiro de Segurança Pública, 2017. Disponível em <http://unesdoc.unesco.org/images/0026/002606/260661por.pdf>. Acesso em 20 nov. 2020.

BRASIL. Relatório Final CPI Assassinato de Jovens, 2016, 155p. Disponível em: <https://www12.senado. leg.br/noticias/arquivos/2016/06/08/veja-a-integra-do-relatorio-da-cpi-do-assassinato-de-jovens $>$. Acesso em 17 nov. 2020.

BERTOLI, Patrícia Pereira; Cristiane Magalhães BISSACO. O Círculo de Bakhtin e a Escola de Frankfurt no enfrentamento da crise civilizatória atual. Ipiseitas. v.4, n.1, p.151-171, jan-jul, 2018. Disponível em: <http:// www.revistaipseitas.ufscar.br/index.php/ipseitas/article/view/182>. Acesso em: 17 nov. 2020.

CAMPOS, Jonas. Funcionária de supermercado abordada por João Alberto diz em depoimento que ele 'parecia estar furioso com alguma coisa. G1 GLOBO. Rio Grande do Sul. Disponível em: <https://g1.globo.com/ rs/rio-grande-do-sul/noticia/2020/11/22/funcionaria-do-supermercado-onde-joao-alberto-foi-morto-presta-depoimento.ghtml> Acesso em: 22 nov. 2020. 
COUTO, Mia. E se Obama fosse africano? e outras intervenções. São Paulo: Companhia das letras, 2011.

EVARISTO, Conceição. Becos da Memória. Rio de Janeiro: Pallas, 2017.

FANON, Frantz. Pele Negra Máscaras Brancas. Salvador: EDUFBA, 2008.

FOUCAULT, Michel. História da sexualidade I: a vontade de saber. Tradução: Maria Thereza da Costa Albuquerque e José Augusto Guilhon Alburquerque. 18ª ed. Rio de Janeiro. Graal, 1988.

FOUCAULT, Michel. Estratégias poder-saber. Organização e seleção de textos Manoel Barros da Motta; Tradução: Vera Lucia Avellar Ribeiro. 2 ed. Rio de Janeiro: Forense Universitária (Coleção Ditos e escritos IV), 2006.

FOUCAULT, Michel. Vigiar e punir: nascimento da prisão. Rio de Janeiro: Vozes, 2014.

GILROY, Paul. Atlântico negro: modernidade e dupla consciência. São Paulo: Editora 34, 2012.

INTERNACIONAL, Estado de Minas. Georg Floyd morreu por asfixia, conclui laudo encomendado pela família. Disponível em: <https://www.em.com.br/app/noticia/internacional/2020/06/01/interna_internacional,1152760/floyd-morreu-por-asfixia-conclui-laudo-encomendado-pela-famili.shtml>. Acesso em: 20 nov. 2020 .

KOPENAWA, David. A queda do céu: Palavras de um xamã yanomami. Tradução B. Perrone-Moisés. São Paulo: Companhia das letras, 2015.

LORDE, Audre. Irmã Outside. Belo Horizonte: Autêntica, 2019.

MBEMBE, Achille. Crítica da razão negra. Tradução: Marta Lança. $2^{\circ}$ ed. Portugal: Editora Antígona, 2017. MBEMBE, Achille. Crítica da razão negra. São Paulo: N-1 edições, 2018.

MBEMBE, Achille. Necropolítica: biopoder, soberania, estado de exceção, política da morte. São Paulo: N-1 edições, 2018.

MBEMBE, Achille. Políticas da inimizade. Tradução: Marta Lança. Portugal: editora Antígona, 2019.

MENDONÇA, Jeniffer. O massacre que interrompeu a quarentena no Complexo do Alemão. Ponte Jornalismo, São Paulo, 17 maio 2020. Disponível em: <https://ponte.org/o-massacre-que-interrompeu-a-quarentena-no-complexo-do-alemao/>. Acesso em: 21 nov. 2020.

Nações Unidas. Disponível em: <https://nacoesunidas.org/vidasnegras/ Acesso em: 25 nov. 2020.

RIBEIRO, Djamila. Lugar de fala. São Paulo: Pólem, 2019.

ROSA, João Guimarães. Grande Sertão: Veredas. São Paulo: Companhia das Letras, 2019.

SENNETT, Richard. O Declínio do homem público: As tiranias da intimidade. Rio de Janeiro: Record., 2014.

SIMAS, Luiz. Antônio; RUFINO, Luiz. Encantamento: sobre política de vida. Rio de Janeiro: Mórula Editorial, 2020.

SOUSA, Noémia. Sangue Negro. Rio de Janeiro: Associação dos Escritores Moçambicanos, 2001.

VELLEDA, Luciano. Bia Ferreira põe sua arte a serviço da luta contra o 'sistema opressor'. Disponível em: $<$ https://www.redebrasilatual.com.br/ cultura/2019/12/bia-ferreira-poe-sua-arte-a-servico-da-luta-contra-o-sistema-opressor/>. Acesso em: 25 nov. 2020. 